\title{
LA PARTICIPACIÓN CIUDADANA EN LOS ASUNTOS PÚBLICOS Y SU CONTRIBUCIÓN A LA CALIDAD DE LA DEMOCRACIA. REFLEXIONES AL HILO DE ALGUNAS EXPERIENCIAS PARTICIPATIVAS*
}

\author{
María José Corchete Martín
}

doi: 10.18543/ed-63(2)-2015pp81-109

\begin{abstract}
SUMARIO: 1.- INTRODUCCIÓN: ¿ESTÁ EN CRISIS LA DEMOCRACIA? 2.- LA SOBERANÍA POPULAR DESDE LA ÓPTICA DE LA GOBERNANZA Y EL BUEN GOBIERNO. 3.- LA DEMOCRACIA PARTICIPATIVA ¿REALIDAD O UTOPÍA? REFLEXIONES AL HILO DE LAS NUEVAS EXPERIENCIAS PARTICIPATIVAS. 4.- BIBLIOGRAFÍA.
\end{abstract}

\section{INTRODUCCIÓN: ¿ESTÁ EN CRISIS LA DEMOCRACIA?}

La respuesta a la pregunta no es fácil porque entre otros motivos creemos que no es una pregunta que pueda responderse en un sentido afirmativo ni tampoco negativo de manera absoluta y rotunda. Sin embargo, este interrogante, en cierta medida provocativo, nos va a permitir aproximarnos al actual contexto donde desarrollamos nuestra vida como seres humanos, como ciudadanos, como consumidores, como contribuyentes.., y analizar el problema de fondo que ha llevado a cuestionar, en los últimos años, no la democracia en sí, pero sí su calidad. Principalmente, la desconexión entre la clase políti-

* El artículo es una versión actualizada y completada de la ponencia presentada en el XII Congreso de la Asociación de Constitucionalistas de España, «Participación, Representación y Democracia», celebrado en la Universidad de Salamanca los días 3 y 4 abril de 2014. 
ca y los ciudadanos, un problema que no es nuevo en las democracias vigentes, constituye una de las circunstancias que genera este tipo de preguntas y que nos llevan a reflexionar sobre los factores que contribuyen a esta desafección. Sin duda nos encontramos en una fase histórica compleja en relación con el papel que los ciudadanos deberíamos jugar dentro del Estado. Ello nos lleva de manera natural a hablar de crisis, pero no tanto de la democracia, sino de las relaciones entre Estado y sociedad.

El Estado actual trata de responder, sobre todo en los últimos años, más que a las demandas ciudadanas, a otro tipo de demandas -de los mercados principalmente - con las que la ciudadanía no se siente identificada, en la medida en que no responden a la lógica de un Estado Democrático y Social de Derecho que propugna, entre sus valores esenciales, la igualdad y la libertad. El déficit que en el momento presente vivimos en relación con estos valores ha llevado a los ciudadanos a esa desafección, tratando de buscar, en nuevas opciones políticas, un rumbo nuevo más favorable hacia los valores democráticos y sociales.

Son muchas las circunstancias que han concurrido para haber llegado a esta situación. Nuestra integración en organizaciones internacionales ha reducido considerablemente la capacidad de decisión interna de los Estados, mientras los ciudadanos, como titulares de la soberanía nacional, contemplan con cierta frustración cómo se toman decisiones que afectan de manera profunda y restrictiva a sus derechos sin poder hacer nada al respecto ${ }^{1}$; el sistema electoral, diseñado para la elección de nuestros representantes, mantiene un diseño que no responde a la confianza en la capacidad de elección y control por parte de los ciudadanos, lo que agrava los efectos de esa desvinculación representantes-representados que hoy se manifiesta en la «desafección» reflejada tanto en las calles como en las encuestas; la crisis de los valores esenciales que sustentan nuestra democracia se ven minados con los continuos casos de corrupción política que salen a la luz sin una firme actitud de reprobación por parte de la clase política. Pero sin duda, lo más grave es que nuestros interlocutores tradicionales, los partidos políticos, se han convertido en instituciones elitistas cada vez más desvinculadas de la realidad y este hecho,

\footnotetext{
${ }^{1}$ Un ejemplo lo constituye la experiencia griega que reflejó las dificultades de los equilibrios supranacionales y las decisiones que los mantienen, revelando su fragilidad bajo el perfil democrático interno. Cfr LIETO, S.: «Il rapporto tra il referendum e la democracia della rappresentanza nell'attuale crisis del sistema político», Costituzionalismo.it, Fasc 1/2012 (consultado 13 enero 2014), 2012, pp. 10-11. Por contra, y a través de una nueva fuerza política, el 5 de julio del presente año, se celebró el «ansiado» referendum para la problación griega que esta vez sí mostró al pueblo griego como el verdadero titular de la soberanía nacional,decidiendo sobre temas de especial transcendencia tanto para su presente como para su futuro político, social y económico.
} 
sin duda, altera el funcionamiento del Estado en la medida en que los partidos, en lugar de ser un elemento de enlace, han devenido en una barrera entre pueblo e instituciones (CARlassare, 2003a, 6). Pareciera que la «desconexión postelectoral» responde a la justificación de CONSTANT y SIEYÉS de que «el ciudadano carece de aptitud para ocuparse de cosas comunes....., siendo el diputado el especialista...», entonces, ¿dónde queda el elector durante los cuatro años que dura el mandato? Resulta evidente que hoy la relación representativa se resume en el acto electoral y, una vez depositado el voto, esta relación ya no tiene el más mínimo contenido; es una relación vacía, «alguien desconectado de nosotros tras el momento electoral, gobierna con nuestra representación» (GARRORENA, 1991, 54-55).

Esta idea constituiría el modelo de partida que no ha sido sometido a suficiente crítica y revisión. De hecho, es esta desvinculación la que ha provocado que en las últimas décadas se haya planteado, sobre todo desde la doctrina, la necesidad de una reflexión y una revisión de principios tan nucleares como el principio democrático. Ello pasa, necesariamente, por una relectura de nuestra constitución una vez efectuado un análisis profundo de las circunstancias actuales y de las demandas sociales, enfocadas en los últimos años en introducir e impulsar una nueva forma de entender y poner en práctica la democracia.

Desde el punto de vista de la soberanía popular, la relación entre elegidos y electores parece suspendida por un largo período de tiempo hasta las elecciones, un rito que cada vez convence menos. La idea de democracia permanente o continuidad democrática se presenta verdaderamente como contraria a la democracia de investidura (CARLASSARE, 2003b, 63-64), que sería aún la actualmente vigente en términos generales; sin embargo, las instituciones democráticas debieran ser permanente expresión de la voluntad popular, manteniendo una correspondencia constante con aquellos de los que reciben el mandato, un estrecho ligamen entre información, comunicación, representación política y democracia.

Sin embargo, esta crisis, tanto de los partidos como de la representación, ha provocado en los últimos años un cambio importante en la forma de concebir la democracia. De la democracia de los partidos hemos ido caminando hacia una democracia del público, en la medida en que el ciudadano ya no vota un programa sino que vota a aquel candidato cuyas propuestas le inspiran confianza (B. MANIN, 1997, pp 243-244), y todo ello teniendo en cuenta el papel preponderante que continúan jugando los Partidos Políticos en la competición electoral, como no podía ser de otra manera.

Ciertamente, no solo en el voto está el ejercicio de la democracia, de la soberanía. El derecho de los ciudadanos a participar en los asuntos públicos no se agota con la forma representativa y así, principalmente las nuevas opciones políticas han defendido «nuevas formas de hacer política», precisa- 
mente atendiendo a las demandas de los ciudadanos-electores que reclaman la necesidad de complementar el sistema de democracia representativa con nuevas instrumentos de participación política. Conscientes de la necesidad de recuperar a un electorado «desencantado» con la política y con aquellos que la dirigen, se busca en otras formas de participación directas o semidirectas, recomponer las relaciones entre representantes y representados ${ }^{2}$.

Para poder reflexionar sobre estas cuestiones G. FERRARA $(2009,5)$ considera que debemos partir de la comprensión de la democracia como proyecto histórico que se despliega con pausas y regresiones que pueden ser largas pero nunca definitivas. Se trata de un proceso que discurre reconociendo, desarrollando, difundiendo derechos y, con estos, la igualdad y la libertad, pero «no la libertad abstracta, sino aquella concreta y específica».

Precisamente en este contexto resulta interesante el planteamiento que hace F. Viola (2006, 23-26) a partir de la idea de que el constitucionalismo y la difusión de los derechos fundamentales no parecen ya compatibles con una versión puramente formal de los procedimientos democráticos. Efectivamente, el autor defiende que es en las Constituciones donde se encuentran los valores básicos de la sociedad democrática, y ésta debe saberlos respetar, administrar y desarrollar, preguntándose, entonces, si estas tareas pueden ser adecuadamente resueltas con el puro procedimiento democrático o, por el contrario, si no se requeriría un replanteamiento de este modo político tradicional.

Viola parte de dos modelos de relación entre Constitución y los procedimientos democráticos. Por un lado, la concepción de la «Constitución Custodio») que nos situaría ante la Constitución como límite externo de la democracia, una particular democracia vigilada que debe rendir cuentas y, por otro lado, la «Constitución simiente», precisamente porque la democracia es un proceso histórico, se basa en principios constitucionales que aún no están completos, de hecho, de por sí, serían indeterminados. Así, y partiendo de esta idea, el autor defiende que de las reglas generales habrá que ir, en cada caso, a reglas particulares de aplicación a los casos concretos, una labor compleja que deberá realizarse por las instituciones democráticas. Esta distinción es lo que le lleva a hacer referencia a la Constitución actual como «Constitución simiente» en el sentido de que los valores constitucionales deben ser tomados como razones fundacionales que deben ser desarrollados sobre la base de los contextos sociales y de las circunstancias históricas. A este mo-

${ }^{2}$ Sin embargo para N. BoBBio, no toda crítica a la democracia representativa conduce, sin más, a la democracia directa. El razonamiento es complicado porque este debe girar en torno a dos temas como son, los poderes del representante o ¿cómo representa?, y el contenido de la representación o ¿qué representa? Sobre este razonamiento, vid: Il Futuro della Democrazia, Nuovo politécnico, Ed. Original, Torino, pp. 58 y ss. 
delo le correspondería un tipo de democracia que denomina «democracia agricultora», en cuanto que es a los procedimientos democráticos a los que les toca desarrollar la potencialidad de los principios constitucionales fundamentales, respetando su identidad.

Por ello, de cómo entendamos la Constitución entenderemos la democracia: la Constitución como conjunto de reglas de juego autosuficientes o, si no es posible, entonces debemos revisar profundamente nuestro concepto de democracia. Es por ello por lo que Viola se decanta por el segundo modelo, «Constitución simiente», más adecuado para comprender las relaciones efectivas que existen entre una Constitución y una democracia representativa. La democracia concebida como «aspiración» (U. ALLEGRETTI, 2011, 2).

Sin duda, las consecuencias de adoptar este segundo modelo de constitución se ajustan más al tipo de sociedad actual, una sociedad pluralista que se identifica con el pueblo titular de la soberanía al que hacen referencia las Constituciones actuales. Este pueblo es el que ejerce en términos reales la soberanía, como conjunto de ciudadanos a cada uno de los cuales le corresponde el derecho de participar individualmente o a través de los grupos en que la sociedad se articule (Criado De Diego, 2012, 113). Ello implica, como vamos a analizar en los siguientes apartados, que el ejercicio de la soberanía no puede limitarse a las manifestaciones del pueblo como unidad, ni tampoco, a las que son propiamente políticas, sino a todas las formas participativas en las que se expresa el pueblo como multiplicidad y que son manifestación del pluralismo institucional y social. Ello supone a nuestro parecer, en consonancia con la opinión de Viola (2006) y de CRiado De Diego (2012), a quienes les resulta contradictorio interpretar las referencias constitucionales como numerus clausus, que la Constitución está aún pendiente de una relectura a la luz de las transformaciones económicas, sociales y políticas que deben impulsar la adecuación de la norma fundamental a la realidad. Esto es, repensar otras formas de participación ciudadana y no solamente aquellas mediadas por procedimientos electorales y desde la representación política. Y es que el reconocimiento de un numerus apertus de mecanismos participativos a partir de una interpretación sistemática de nuestra norma fundamental, nos llevaría a una adecuación del principio democrático en términos de fortalecimiento del carácter plural del Estado. El art 1.1 Constitucional que recoge la igualdad, la libertad, la justicia y el pluralismo político como valores superiores del ordenamiento jurídico, constituye la premisa para consolidar los cimientos de nuestro Estado, proyectándose materialmente sobre todos y cada uno de los contenidos constitucionales. El art 9.2 de la Constitución, como mandato a los poderes públicos para promover de manera real y efectiva la libertad y la igualdad del individuo y de los grupos en que se integran, facilitando la participación de todos los ciudadanos en la vida política, económica, cultural y social, deberían marcar otra forma de 
entender «la participación ciudadana» en los distintos contextos socio-políticos que se vayan presentando, en la medida en que ambos preceptos ofrecen un contenido de gran riqueza material que sin embargo, treinta y cinco años después de aprobada la Constitución, no han contado, fundamentalmente desde el ámbito de los derechos de participación, con un desarrollo ajustado a los tiempos y circunstancias. El juego conjunto de ambos preceptos constitucionales debería constituirse en el eje de esa relectura constitucional, a la que hemos hecho referencia, en clave democrática y no sólo eliminando las barreras existentes en relación con determinados mecanismos participativos, sino impulsando y garantizando otras formas más novedosas para ser ejercidas de manera más continuada. En definitiva, lo que se trataría de buscar es lo que FioravANTI (1999,161-162) calificaba como la aspiración a un justo equilibrio entre el principio democrático, dotado de valor constitucional a través de las instituciones de la democracia política y el mismo papel del legislador y del gobierno, y la idea -insita en toda la tradición constitucionalista-, de los límites de la política, a fijar mediante la fuerza normativa de la Constitución y, en particular, a través del control de constitucionalidad siempre más determinante en el ámbito de las democracias modernas. Sin embargo, este mismo equilibrio es inevitablemente inestable y está sometido a tensiones de distinto género; fundamentalmente la provocada por la relación entre los sujetos protagonistas.

En cualquier caso conviene insistir en que la idea de democracia permanente debe ser construida desde la Constitución y desde una concepción abierta de la sociedad en el sentido del art 9.2 CE. Este es el modelo pluralista defendido por HÄBERLE $(2002,103)$, «sociedad abierta-orden político pluralista», y también la idea de «nuevo constitucionalismo» a la que se refiere Gomes CANotilho $(2010,323)$ para justificar que las nuevas formas de modernidad política y económica obligan a los cultivadores del Derecho Constitucional a prestar más atención a los problemas político-constitucionales como son, por ejemplo, la crisis del principio representativo o del principio democrático; y es que, para el autor portugués, el nuevo constitucionalismo, en realidad, acentúa lo que el constitucionalismo siempre ha sido, el campo de los «kämpfs parole» y de la solución política para problemas políticos fundamentales.

\section{LA SOBERANÍA POPULAR DESDE LA ÓPTICA DE LA GOBERNANZA Y EL BUEN GOBIERNO.}

Los conceptos de gobernanza y buen gobierno no son conceptos nuevos. Desde hace ya varias décadas y como consecuencia del debilitamiento del carácter democrático de los Estados, estos conceptos «han sido rescatados» de momentos históricos en los que constituían un auténtico modelo de rela- 
ción entre el poder y la sociedad civil. Hoy se han convertido en un modelo de referencia para poder llevar a cabo un replanteamiento de estas mismas relaciones en el Estado ${ }^{3}$. Las ideas de libertad, autogobierno, el sentido de lo cívico, la búsqueda del bien común...como objetivos a alcanzar; esto es, una relación en sentido horizontal alejada de los actuales parámetros de verticalidad que hoy en día impregnan, de manera generalizada, las relaciones de poder dentro del Estado.

Bien es verdad que ambos términos, Gobernanza y Buen Gobierno, han sufrido un gran estiramiento conceptual. Siendo dos conceptos diferentes, son manejados de manera complementaria para hacer referencia a un «ideal» de democracia y, sobre todo, a nuevas maneras de gobernar a partir de un mayor protagonismo de la sociedad civil ${ }^{4}$. En los últimos años y sobre todo en el contexto de crisis en el que vivimos, se ha ido revelando poco a poco la importancia que para la calidad de la democracia tendría el estrechar y reforzar los vínculos entre sociedad e instituciones a la hora de tomar decisiones en el ámbito de lo público aunque, bien es verdad que en la práctica, sin la iniciativa y el apoyo de estas, resulta difícil poner en marcha experiencias de democracia participativa desde abajo ${ }^{5}$.

La participación aparece como un elemento clave, que no único, de la gobernanza (ROMERO Y FARINÓs, 2011), mientras que el buen gobierno se centra, en mayor grado, en el elemento cualitativo, tanto desde una perspectiva legalista como ética y, en este sentido para CASTEL GAYÁn $(2013,169)$ «funcionarían como principios que guían la acción política, asumiendo un doble papel o función de instrumento orientador y también de control» ${ }^{6}$. Una

${ }^{3}$ Precisamente Quentin SkInNER, en su obra «el artista y la filosofía política», nos acerca a las ideas de Gobernanza y Buen Gobierno a través de los frescos que en 1337 pintara Lorenzetti para la Sala dei Nove del Palacio Comunal de Siena, así como a las Teorías Republicanas prerrenacentistas conocidas como doctrinas del Buen Gobierno, contraponiendo el buen gobierno y su decadencia, el mal gobierno. Vid.: SKINNER, Q.: El artista y la filosofía política. El Buen Gobierno de Ambrogio Lorenzetti, 2009, pp. 9 y ss.

${ }^{4}$ Para BobBIo, N. los criterios con los que el buen gobierno se ha distinguido del mal gobierno son, sobre todo, dos: el gobierno para el bien común distinguido del gobierno para el bien propio, y el gobierno según las leyes establecidas, distinguido del gobierno arbitrario, cuyas decisiones son tomadas fuera de toda regla preconstituida. BoBBIO, N.: El Futuro de la Democracia, Plaza\&Janés, 1985, p. 221.

5 Vid Cocco, G.: «Federalismo municipale partecipato», Costituzionalismo.it, Fascicolo 2/2009), 2009, p. 27, (consultado 12/7/2013).

${ }^{6}$ Castel Gayán, S.: para el autor, el buen gobierno implica además, en el ámbito institucional, la promoción de espacios participativos, de diálogo y de cooperación, y en el ámbito de las políticas públicas, la promoción de aquellas políticas y programas que faciliten a la ciudadanía la comprensión, el debate y el análisis ilustrado de las decisiones que les afectan. Vid.: CASTEL GAYÁN, S.: «Reflexiones sobre el marco normativo del Buen Gobierno», Cuadernos Manuel Giménez Abad, núm. 6, diciembre 2013, pp. 168-180. 
nueva forma de gobernar a través de normas que fomenten la transparencia, la eficacia, la objetividad, la participación, el control y, en definitiva, el bien común. Ambos conceptos nos llevan, como hemos apuntado, hacia una comprensión horizontal del poder que rompe con la situación de hegemonía vertical que, cada vez con mayor frecuencia, nos va mostrando sus debilidades y sus efectos perniciosos para la calidad democrática. En realidad, lo que se coloca en el punto de mira y que lleva a la doctrina a incidir sobre estos conceptos hoy, no es ni el Estado ni su autoridad ni su ley, sino la soberanía representativa que es la que en realidad se encuentra directamente herida (CAPOGRASSI, 1922).

Es el ámbito de la ciudad el que se ha mostrado más propicio para aplicar las ideas de gobernanza y buen gobierno en la práctica. Su impulso lo encontramos en el marco internacional y más concretamente de la mano de la Carta Europea de Autonomía Local de 1985. Esta Carta establecía ya como objetivos programáticos dentro del Consejo de Europa el reconocimiento, la promoción y la garantía de un estándar común y uniforme del principio de autonomía local en todos los Estados miembros. Para ello el texto incidía en la autonomía local como derecho de la colectividad local, así como en la idea de legitimidad democrática, haciendo referencia a la democracia representativa pero también a otras formas de participación directa de los ciudadanos «donde esté permitido por la ley», dejando por tanto en manos de los Estados el cuándo y el cómo poner en marcha mecanismos de participación. El impulso a la autonomía local también quedaba reflejado cuando la Carta hacía un reclamo a la necesidad de atribuir a las entidades locales no sólo un núcleo básico de competencias, sino también de recursos financieros suficientes sin los cuales esta atribución quedaría vacía e inútil; de igual modo incidía en la necesaria colaboración entre entidades locales así como a su relación con las entidades regionales y con el Estado. La garantía de la defensa judicial de la autonomía local cerraba esta Carta.

La opinión unánime en relación con la idoneidad del ámbito municipal para la práctica de instrumentos de democracia participativa que mejoren la calidad de las democracias actuales, ha llevado a justificarla a través de muy diversos argumentos, pero sin duda es la idea del «poder visible» de N. BoBBIO $(1985,11)$ la más clara cuando defiende que «tanto más visible es el poder cuanto más cerca nos hallamos de él», resaltando el valor espacial para obtener una mayor visibilidad tanto de las actuaciones administrativas como de las decisiones de nuestros gobernantes. Para el autor la democracia se puede definir de las más diversas formas, pero no hay definición de la misma que pueda dejar de lado entre sus características la inclusión de la visibilidad o la transparencia del poder. Por esta razón, la democracia de «proximidad» se ha convertido en hábitat idóneo para los instrumentos de democracia participativa. De hecho el modelo local resulta un ámbito donde debería llevarse 
a cabo este tipo de democracia de forma natural, en la medida en que solo la proximidad con el territorio y la posibilidad de efectiva incidencia y de control que sobre el gobierno pueden tener los ciudadanos, lo permite, incluso de forma «no episódica» (CoCCO, 2009, 78).

La influencia de la Carta se dejó notar años después en la Ley 57/2003 de 16 de diciembre de Medidas para la Modernización del Gobierno Local, si bien con más intención que eficacia real.

Esta Ley trató de fijar unos estándares mínimos de participación, de aplicación a todos los municipios a través de los reglamentos orgánicos de participación y, en relación con las grandes ciudades, introduciendo órganos como el Consejo Social de la Ciudad, de carácter consultivo para el desarrollo local y la planificación urbana, la Comisión de Sugerencias y reclamaciones, para la defensa de los derechos de los vecinos, órganos de gestión desconcentrada, como los distritos, así como referencias a las nuevas tecnologías con la finalidad de facilitar la comunicación entre los Ayuntamientos y sus ciudadanos.

En general, esta Ley fue recibida positivamente comparándola con la situación anterior donde se daba prioridad a elementos más de corte institucionalista (Subirats, 2004) ${ }^{7}$; sin embargo, en la práctica, la respuesta del legislador no resultó del todo satisfactoria a pesar de que el propio texto detectó bien los problemas a los que pretendía dar respuesta. De hecho la exposición de motivos refleja una nueva realidad a la que se pretendía responder cuando señala que la antigua normativa se encuentra «desbordada por las exigencias de una vida local dinámica y rica, profundamente influida por las importantes transformaciones sociales, económicas, culturales que han experimentado los municipios españoles a lo largo de las últimas décadas». Esta dinámica es lo que propicia, para el legislador, la necesidad de «responder a la exigencia de un debate político abierto y creativo sobre las principales políticas de la ciudad».

Entre las críticas que se le hicieron a esta ley podemos citar, en primer lugar y con carácter general, su falta de concreción visible en múltiples puntos, pudiendo citar a modo de ejemplo un tema tan importante como son los gastos que estas prácticas generan, como pueden ser aquellos relacionados con la aplicación de las nuevas tecnologías a la vida municipal (SUBIRATS, 2004), cuestión sobre la cual ya incidía la Carta Europea de Autonomía Local; además, los distritos no resultan ser realmente iniciativas descentraliza-

${ }^{7}$ Para el autor, la Constitución trató de reforzar la falta de tradición democrática y participativa del país con una clara apuesta a favor de las instituciones como centros de articulación y representación política y de los partidos políticos como protagonistas de una actividad social que debería alimentar y legitimar el funcionamiento del sistema (pp. 40-41). 
doras en términos políticos, que hubiera sido lo deseable, y el tratamiento que se hace en relación con la composición del Consejo Consultivo de la Ciudad resulta demasiado amplio teniendo en cuenta que, de todos los órganos que se introducen en esta Ley, resulta el más participativo; y en cuanto a las iniciativas ciudadanas, se opta por una regulación muy restrictiva. En definitiva, el objetivo de la gobernanza y el buen gobierno en la ciudad no se consigue con esta ley porque en su contenido sigue predominando una vertiente institucional en estos mecanismos de «participación», con lo que tampoco se consigue una auténtica integración entre gobernantes y gobernados, entre otros motivos, porque los mecanismos introducidos no son estrictamente participativos. Sin embargo, bien es verdad que, en la práctica, el balance que puede hacerse en relación con la aplicación concreta de esta ley es muy diferente en función del impulso que cada gobierno local haya querido darle (ZAFRA, 2004). Por ello, resulta de vital importancia el papel de los actores políticos, en la medida en que la iniciativa de los procedimientos participativos y, sobre todo su calidad, va a depender en gran medida del impulso de las autoridades que son «quienes controlan el proceso, definen la agenda, fijan las reglas del juego y condicionan el acceso de los actores sociales al proceso de discusión» (RUANO DE LA FuENTE, 2010, 106).

La nueva Ley de Racionalización y Sostenibilidad de la Administración Local, aprobada en el mes de diciembre del año 2013, supuso a todas luces un retroceso en el camino andado en la medida en que rompe con el espíritu de la Carta Europea de Autonomía Local y con el avance, aunque pequeño, que supuso la Ley de Modernización del Gobierno Local para impulsar la autonomía en las ciudades, ya que abre la posibilidad de que los municipios pierdan competencias por la aplicación del nuevo límite constitucional de la estabilidad presupuestaria, hecho que sin duda, como apuntó el Consejo de Estado en su Informe, redundará en perjuicio de la autonomía municipal que «puede verse cuestionada como consecuencia del eventual vaciamiento competencial de los municipios y por el hecho de que sus competencias pasen a entidades locales de representación indirecta como son las Diputaciones Provinciales $\rangle^{8}$.

De nuevo nos enfrentamos a un problema de actitud y sobre todo de capacidad de liderazgo para impulsar un mayor protagonismo de los ciudadanos en la toma de decisiones; una verdadera integración entre gobernantes y gobernados en la búsqueda de «ese bien común» al que hacen referencia las ideas de gobernanza y buen gobierno y que debería concretarse en una auténtica coimplicación de todos, ciudadanos y poderes públicos, en la mejora de la gestión pública, de la cohesión social y, en definitiva, en el fortalecimiento

${ }^{8}$ Informe del Consejo de Estado, de 26 de junio de 2013 (Anteproyecto de Ley de Racionalización y Sostenibilidad de la Administración Local). 
del carácter democrático. Aún así, no debemos obviar, como nos lo recuerda Ahlert $(2007,6)$ «...que una verdadera ciudadanía, ideal máximo de los derechos humanos, exige el ejercicio de derechos y deberes. Esto significa que cada individuo debe fomentar la búsqueda y la construcción colectiva de los derechos». Así, el ejercicio de la responsabilidad con la colectividad, el cumplimiento de reglas y de normas de convivencia, la búsqueda efectiva de participación en la política para controlar a sus gobiernos elegidos dentro de principios democráticos, serían algunos ejemplos de deberes que contribuirían al fortalecimiento de una sociedad más democrática. Sin embargo, compartimos la reflexión de CASTEL GAYÁN (2013) cuando sostiene que la desafección cívica y el descenso en la participación electoral reflejan el malestar y el desencanto hacia la democracia representativa. De ahí la importancia de abrir nuevos espacios que complementen el sistema representativo, devolviendo al ciudadano la confianza en el mismo. Sin duda este es el objetivo: la necesidad de introducir nuevas formas y nuevas prácticas que combinen la democracia representativa con aquella participativa, con la finalidad de mejorar la cualidad de la primera y contribuir a la de la segunda, porque estas formas de democracia deben ser profundamente diferentes y sin embargo compatibles. Se podría hablar de una relación de continuidad entre ellas, también de la democracia deliberativa, y no de alternancia, precisamente porque la democracia necesita de mecanismos de decisión basados en lógicas diversas, entre ellas, la deliberación pero también, el voto, la negociación y el interés personal ${ }^{9}$.

\section{DEMOCRACIA PARTICIPATIVA ¿REALIDAD O UTOPÍA? REFLEXIONES AL HILO DE NUEVAS EXPERIENCIAS DE PARTICIPACIÓN CIUDADANA}

El Derecho Comparado nos ofrece un banco de pruebas muy valioso para experimentar y reflexionar en torno a instrumentos de democracia participativa que puedan aportar el impulso que las democracias actuales necesitan, tanto en términos de legitimidad como de cultura cívica.

Se trata de una modalidad relativamente reciente en Europa donde los ciudadanos individualmente y no necesariamente reunidos en forma asociativa, participan en procedimientos públicos que cuentan con momentos abiertos, con el objetivo de influir de manera efectiva en las decisiones finales (U. AlLEGRETTI, 2011). Se trata de prácticas participativas muy variadas que se van diseminando hasta ser recibidas y adaptadas en diversos

9 Sobre la relación entre estas tres formas de democracia, vid BIFULCO, R.: «Democracia deliberativa y democracia participativa», www.astrid-online, pp. 4-6, 2010 (consultado $7 / 11 / 13)$. 
lugares con los mismos problemas y dificultades. Una nueva forma de regular y dar respuesta a conflictos sociales integrando a los actores políticos con la sociedad misma a través de lo que BlANCO y GoMÁ $(2003,13)$ han denominado «gobierno local relacional», entendido como «aquel que sitúa la gestión municipal en términos de deliberación e implicación ciudadana pluralista en las decisiones públicas locales», esto es, gobiernos abiertos basados en las ideas de proximidad, transparencia y sensibilización. Por tanto, nuevas formas de gestión y de gobierno que vendrían a complementar a una democracia fundamentalmente institucional, intentando atenuar, en alguna medida, una representación que a todas luces se muestra imperfecta. Sin embargo, muchas son las críticas vertidas en relación con la práctica de estos instrumentos, siendo quizá las más frecuentes aquellas centradas principalmente en los costes económicos que generan, en la lentitud que introducen este tipo de instrumentos participativos en la toma de decisiones, así como también en la manipulación a la que pueden verse sometidos los participantes. Cuestiones todas ellas que trataremos de abordar en las siguientes páginas.

Los dos instrumentos de democracia participativa más interesantes a nuestro parecer y en los que centraremos nuestras reflexiones serán los presupuestos participativos y los debates públicos ${ }^{10}$. No obstante, el objetivo de este apartado no es centrarnos de manera particular y exhaustiva en cada uno de estos mecanismos de democracia participativa, sino en tratar de llegar a los requisitos que, a nuestro juicio, deberían darse de manera «inexcusable» en este tipo de procedimientos para poder hablar de un verdadero impulso en la finalidad perseguida; esto es, acercarnos a las ideas de gobernanza y buen gobierno en términos reales y efectivos.

Los Presupuestos Participativos a nivel local en Europa parten de las experiencias latinoamericanas y, más concretamente, del modelo de Porto Alegre porque es el más antiguo, el más conocido y la experiencia más consolidada, aunque la metodología es diferente, obviamente, porque los contextos en donde se aplican también lo son.

El elemento común que subyace a estas experiencias nacidas del referente brasileño es que este instrumento supone una forma participada de diseñar el presupuesto local o parte del presupuesto local. En Europa nos encontramos con procedimientos de Presupuestos Participativos más informales, con reglas menos precisas, siempre impulsados desde arriba (top-down) y, en general, con un carácter más consultivo que deliberativo, a diferencia del modelo de Porto Alegre, impulsado desde la misma sociedad (bottom-up) y

${ }^{10}$ En estos y, en general, en los diversos procedimientos participativos, pueden existir momentos de superposición con otras formas de participación (momentos de tipo representativo o de democracia directa). 
con un carácter puramente deliberativo ${ }^{11}$. En nuestro país existen experiencias ya consolidadas y otras, en cambio, se fueron abandonando como consecuencia, bien de la alternancia política, bien por la pasividad ciudadana. Siempre en ciudades de pequeño o mediano tamaño ${ }^{12}$.

En cuanto a los Debates Públicos, las experiencias son muy diferentes. A menudo son resultado de «hibridaciones» entre modelos distintos. Los marcos regulativos son muy variados y el grado de participación resulta, de igual modo, bastante variable. Quizá el modelo de referencia en Europa sea el modelo de Debate Público francés sobre grandes obras. La finalidad del Debate Público es que las instituciones políticas representativas llamadas a decidir, lo hagan de manera responsable. Sin embargo, los órganos representativos son los únicos legitimados para tomar una decisión, estando «llamados» a justificar su elección indicando las razones que les llevan a adoptarla, alejándose o separándose de las indicaciones derivadas del debate ${ }^{13}$.

${ }^{11}$ Sobre la experiencia de Porto Alegre, vid entre otros, Allegretti, G.: l'insegnamento di Porto Alegre: autoprogettualità come paradigmo urbano, Alinea, Florencia, 2003; BLANCO, I.: «Presupuestos participativos y democracia local: una comparación entre las experiencias brasileñas y españolas», documento presentado en el VII Congreso Internacional del CLAD sobre la Reforma del Estado y de la Administración Pública, Lisboa, 8 al 11 de octubre, 2002; Gret, M. y Sintomer, Y.: Porto Alegre: la esperanza de la democracia, Debate, Barcelona, 2003; SAntos, B. DE Sousa (coord.) (2002); VILLASANTE, T.R. y GARRIDO, F. I. (coords) (2002).

${ }^{12}$ La experiencia de Porto Alegre ha sido hasta el momento la más influyente en Europa y especialmente en España. Se basa en dos dimensiones, territorial (con asambleas y/o gremios de barrio o de sector) y temática (sobre diferentes políticas públicas); articula el nivel micro local (del barrio o de la aldea) y el de la ciudad así como asambleas abiertas a todos los ciudadanos y consejos de delegados que constituyen la cumbre del proceso y lo monitorean; utiliza criterios formales de distribución de los recursos dentro del marco de un reglamento explícito que puede ser modificado por los participantes; necesita un ciclo organizado de discusiones y toma de decisiones durante todo el año, tiene un valor deliberativo, permitiendo la discusión entre ciudadanos y gobierno local principalmente sobre presupuestos de inversión. Cfr Sintomer, Y.: «Los Presupuestos participativos en Europa: retos y desafíos», Rev. del CLAD Reforma y Democracia, n. ${ }^{\circ} 31$, Febrero 2005, Caracas, 2005, pp. 1-17.

${ }^{13}$ Las primeras experiencias en Italia de Debate Público sobre grandes obras fueron dos: el Debate de Montaione, en la Toscana en 2007, y el Debate de la «Gronda di Ponente» en el año 2009 en Génova, ambas impulsadas desde la colaboración poder políticociudadanos. El primero de ellos supuso un interesante proceso participativo sobre un grande y arriesgado complejo turístico llevado a cabo con buenos resultados antes de la entrada en vigor de la Ley Regional de 2007. En el segundo supuesto, la discusión sobre la construcción de una gran autopista que atravesaba la ciudad de Génova, fue promovida por el Comune de dicha ciudad, también en ausencia de regulación al respecto, de acuerdo con la empresa responsable de la autopista. El resultado fue un nuevo proyecto de trazado consensuado por los ciudadanos y la empresa que modificó aquellos elaborados previa- 
Tanto en los Presupuestos Participativos como en los Debates Públicos el objetivo no es otro que crear un recurso de discusión pública para encontrar soluciones, lo más compartidas posibles, en torno a decisiones importantes que van a afectar a una comunidad territorial (U. AlLEgretti, 2011). En ambas prácticas, independientemente de las metodologías utilizadas, existen una serie de elementos que deben ser tenidos en cuenta si lo que se pretende es tomar en serio el impulso de una democracia de calidad a través de instrumentos de democracia participativa realmente efectivos. Por ello, resulta conveniente detenernos en cada uno de ellos a partir de las experiencias vividas en contextos muy próximos al nuestro, precisamente para valorar su aportación. Será la experiencia italiana la que tomaremos como hilo conductor del presente trabajo y, más concretamente, la experiencia Toscana por ser la más adecuada para nuestro objetivo.

En Italia el impulso de estas prácticas vino de la mano de las Regiones. Por tanto, en términos generales, son las leyes regionales las que introducen y apoyan instrumentos concretos de democracia participativa en el ámbito regional y local.

Merece especial mención la Ley 69/2007 de la región de la Toscana de «Promoción de la participación en la elaboración de las políticas regionales y locales», precisamente porque con esta ley se quiso «experimentar» en este tipo de prácticas participativas, tomándose muy en serio el objetivo de reforzar la democracia en estos ámbitos. Por ello esta Ley nació con fecha de caducidad para que transcurrido ese tiempo, unos cinco años aproximadamente, pudieran solventarse las lagunas y los problemas que se hubieran detectado en la práctica a través de un nuevo texto legal ${ }^{14}$. El experimento trajo consigo la celebración de 116 procesos participativos con resultados no siempre fáciles, pero que sirvieron para tratar de perfeccionarlos a través de la Ley 46/2013 de «Debate Público Regional y promoción de la participación en la elaboración de Políticas Regionales» que finalmente perfiló estas prácticas en esta Región.

En cuanto a los elementos que deben de tenerse en cuenta para que estos mecanismos participativos no resulten frustrantes desde su origen, debemos hacer algunos comentarios al respecto. No obstante, conviene insistir en que su tratamiento y su eficacia dependerán, al menos en gran medida y como

mente, y que supuso para la ciudad frenar la demolición de un gran número de viviendas, máxima preocupación de los ciudadanos (de 900 viviendas que debían ser demolidas, se pasó a sólo 90 con el último proyecto aprobado). Cfr BoBBIO, L., «As especifidades do debate público sobre as grandes infraestruturas. O caso de Génova», Revista Crítica de Ciências Sociais, 91, URL http://rccs.revues.org/4201, 2010, pp. 189-203, (consultado 15-10-2014).

${ }^{14}$ Resolución del Consejo Regional 168/2012, de 29 de diciembre. 
hemos reiterado, del impulso que se les quiera dar por parte de los responsables políticos ${ }^{15}$.

De esta forma, si lo que se busca es normalizar el diálogo con la sociedad e ir creando una cultura cívica y una auténtica cultura política de diálogo, evitando que sean experiencias esporádicas, entonces debería insistirse en su carácter permanente $^{16}$. Así lo pretende la Ley regional de la Toscana de 2013 al introducir este carácter de manera expresa cuando considera la participación como una fase ordinaria del procedimiento de decisión de las instituciones y, por tanto, justificando este momento en aras de la mejora de la calidad de las decisiones institucionales.

Este carácter permanente implicó hacer frente al siempre complejo problema de la financiación que, en la mayoría de los casos, se coloca como uno de los principales impedimentos para la práctica de estos instrumentos participativos. La Ley Toscana concreta este aspecto dejándolo en manos de la Región ${ }^{17}$.

${ }^{15}$ Bien es verdad, como apunta N. Vizioli haciendo referencia a la tripartición entre democracia representativa, directa y participativa enunciada por A. Pizzorusso (1982), que aunque la democracia participativa atribuye la decisión final a los representantes, permite sin embargo la intervención de los destinatarios de la decisión en el proceso decisorio, no como una intervención opositora, sino necesariamente como una intervención colaboradora, muy adecuada para describir también la relación que debe existir en estos casos entre los representantes y la sociedad. Vid.: Vizioli, N.: «La democracia participativa en la Legislación regional italiana», Revista catalana de dret públic, n. ${ }^{\circ} 48,2014$, pp. 187-205.

${ }^{16}$ El texto único básico italiano sobre los entes locales 267/2000 ya enunciaba un principio de participación popular válido para la vida general de los Comunes, más débilmente proyectado sobre las provincias. Incluso un cierto número de administraciones locales fueron más allá, sintiéndose de algún modo autorizadas directamente por la Constitución para experimentar recursos participativos de mayor significado bajo la idea de mayor democratización desde la exigencia de asegurarse una mejor legitimación popular o buscar remedios a su ineficiencia ante los conflictos que se pudieran generar.

${ }_{17}$ Buena prueba de la importancia de este carácter permanente para ir creando una cultura cívica y política en una sociedad lo encontramos precisamente en Brasil. Allí recientemente se pusieron en marcha instrumentos de democracia participativa en el ámbito local, a los que hemos hecho referencia, y ha sido precisamente su permanencia en el tiempo lo que ha permitido que desde hace muy pocos años se vengan desarrollando las llamadas «Conferencias de Políticas Públicas» como instrumentos de participación y deliberación a nivel nacional. Estos nuevos instrumentos sin duda no están exentos de problemas, pero nos encontramos ante una nueva experiencia orientada hacia la misma finalidad: enriquecer la democracia y no ya sólo en el ámbito de la ciudad, sino proyectado en un ámbito mucho más extenso y complejo como es el nacional. Cfr RAMOS, A. y FARIA, C.F.: «Las Conferencias de Políticas Públicas en Brasil: hacia un sistema integrado de participación y deliberación a nivel nacional», Revista Española de Ciencia Política,

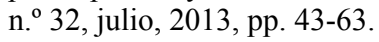


En relación con los actores intervinientes, es importante tener en cuenta que una de las finalidades perseguidas con estas prácticas es la de involucrar al ciudadano en la política; por ello y, al menos en principio y con carácter general, estos procedimientos deben ser lo más inclusivos y democráticos posibles. En la mayoría de las experiencias se suele utilizar un lenguaje difuso al respecto aunque el objetivo, en mi opinión, debe ser el de tratar de garantizar la cohesión social dentro de este ámbito territorial, por lo que sería muy importante que estos procedimientos fueran capaces de superar las asimetrías que se producen en las ciudades como consecuencia de la multiculturalidad existente y, en general, de la complejidad que caracteriza a las sociedades actuales ${ }^{18}$. Sin embargo, las opiniones al respecto, tanto doctrinales como de carácter político, son muy variadas, considerando algunas de ellas que las decisiones que se puedan tomar a través de este tipo de procedimientos serán más representativas de los intereses en juego cuanto más inclusivos sean (LeVINE y Molina, 2007) o, desde una posición más realista, las que alegan que una participación de todos es irrealizable sobre el plano práctico, pudiendo revelarse como obstáculo para la eficacia de la deliberación (L. BobBio, 2002). Sin embargo, por la finalidad que se pretende con estos procesos, la participación debería abrirse, con carácter general y en principio, a todos los ciudadanos censados en el respectivo ámbito territorial del que se trate, en la medida en que en ellos concurrirá algún tipo de interés sobre el territorio y porque las consecuencias de la decisión adoptada también les afectará en alguna medida. En este sentido resulta determinante que el ciudadano no sea excluido de la toma de decisiones al margen del proceso electoral. De ahí la importancia del carácter inclusivo de estos procesos, a pesar de que algunas experiencias son limitadas o utilizan, como hemos apuntado, un lenguaje ambiguo para poder intervenir, recogiendo sus propios mecanismos de selección; de esta forma podemos encontrar diversos criterios para la elección de los participantes como puede ser la selección de tipo causal, específica, por sorteo, etc ${ }^{19}$, todas ellas siempre cuestionables pero, en ocasiones,

18 Para L. BobBio el carácter democrático del proceso plantea el problema del acceso al mismo, que en la democracia deliberativa se plantea bajo el principio de inclusividad total como complemento o superación de la democracia representativa, ya que los mecanismos tradicionales de la representación no aseguran que en una asamblea electiva estén presentes todos los puntos de vista relevantes, ni que las preferencias ciudadanas estén reproducidas con la misma intensidad con la que se manifiestan en la sociedad. Vid.: BobBio, L.: «Come smaltire i rifiuti. Un esperimento di democrazia deliberative», Stato e Mercato, n. 64, 2002, p. 106.

${ }^{19}$ Cfr L. BOBBio apunta hacia la búsqueda de un equilibrio a la hora de seleccionar a los «deliberatori»: ciudadanos comunes y ciudadanos que tengan un interés en el asunto. La Ley Toscana de 2013 confirma la regulación del 2007 adoptando el criterio de máxima inclusividad, estableciendo en su art 2 que los titulares del derecho de participación son 
también justificables, no como criterios rígidos sino flexibles y alternativos, siempre en función de las circunstancias, temáticas, grado de afectación, etc.

Generalmente suelen ser dos los colectivos que con mayor frecuencia quedan marginados en este tipo de procedimientos, los jóvenes y los inmigrantes ${ }^{20}$. Resulta especialmente curioso cómo algunas experiencias participativas, como por ejemplo la recogida en la Ley del 2013 Toscana, confirma la exclusión de los grupos sociales organizados, así como de las asociaciones $^{21}$. La justificación a esta exclusión por parte del legislador regional no es otra que la de impedir la presencia incluso de asociaciones como partidos políticos o sindicatos, dando absoluta prioridad a la presencia de intereses individuales. La Ley del 2013 exige a las asociaciones para poder participar, demostrar tener el apoyo individual requerido, evitando, por un lado, atribuir a los grupos organizados una presunción de representatividad a priori y, por otro lado, que puedan llegar a monopolizar los procedimientos participativos favoreciendo la representación de intereses que son ya fuertes y estructurados (U. AllegretTI, 2011) (CATALDI, 2008). Esto es, optar por procedimientos participativos ajenos a la capacidad de influencia de los partidos políticos, tratando de evitar la manipulación de los participantes. Así, la Ley Toscana recoge el concepto de «ciudadanos» en sentido amplio, favoreciendo por

los ciudadanos residentes y los extranjeros o apátridas, residentes regulares, las personas que trabajan, estudian, habitan de manera no permanente en el territorio interesado, así como todas las demás personas que tengan un interés respecto al territorio en cuestión o en el objeto del procedimiento participativo y que su intervención resulte útil en el proceso mismo. Vid.: BobBIo, L.: «Come smaltire i rifiuti. Un esperimento di democrazia deliberative», Stato e Mercato, n. 64, 2002, p. 20.

${ }^{20}$ De hecho, para RUANO DE LA FUENTE $(2010,106)$, los procesos participativos son asimétricos por varios motivos, y precisamente uno de ellos reside en la diferente influencia de los grupos participantes, hecho que puede llevar a la exclusión de los grupos más vulnerables. Vid.: RUANO DE LA FUENTE, J.: «Contra la participación: discurso y realidad de las experiencias de participación ciudadana», Política y Sociedad, 47, 2010, p. 106.

Sobre el problema de los desequilibrios en la participación como un fenómeno constante en las experiencias de Debate Público, tanto en Francia como en Italia, vid BoBBIO, L, «Dilemmi della democracia participativa», Democrazia e Diritto, 44, 2006, p.11-26.

${ }^{21}$ En nuestro país, por ejemplo, Albacete diseña los Presupuestos Participativos con los colectivos como protagonistas en lugar de los ciudadanos individualmente, o Puente Genil, en Andalucía, que combina a través de un modelo mixto, la presencia de asociaciones y ciudadanos individuales desde una posición más conciliadora. En cualquier caso, las metodologías mixtas también podemos verlas en América Latina, aunque no es la regla general, siendo la experiencia de Belo Horizonte la más conocida. Sobre estas experiencias y los actores participantes, FonT, J. (Coord.); Ciudadanos y decisiones públicas, Barcelona, Ariel, 2001; Ganuza Fernández, E. Y Alvares de Sotomayor, C. (dirs), Democracia y Presupuestos Participativos, Icaria, Barcelona, 2003; PÉRez CASTEll, M.: «La experiencia de los presupuestos participativos en Albacete», Temas para el Debate, n. ${ }^{\circ} 113$, abril, 2004, pp. 54-57, entre otros. 
tanto este tipo de participación individual frente a la asociativa, fundamentalmente de carácter político.

En cuanto al momento abierto, la fase deliberativa, supone una oportunidad para el debate, para la discusión, para hacer política tratando de llegar al consenso a través de la argumentación y «del peso de las razones». Una participación que busca el diálogo abierto. Es esta característica la que lleva a considerar a estos instrumentos mucho más atractivos que a otros como, por ejemplo, el referéndum, que no permite plantear los problemas más que en la forma de sí o no, por lo que se obstaculiza el compromiso y favorece el choque y, precisamente por estos motivos resulta más adecuado para dirimir controversias sobre los principios que para resolver conflictos de interés (N. BoBBIO, 1985, 13).

Bien es verdad que el voto, en estas experiencias, no debe quedar excluido (U. AlLEGRETTI, 2011, 12) en la medida en que pueden darse situaciones complejas, bien por la temática del procedimiento, bien por la polarización de las posturas defendidas. En este sentido y para tratar de garantizar la esencia de este tipo de instrumentos que cuentan con momentos abiertos, se trata de evitar el uso alternativo de mecanismos que permitan tomar una decisión más rápidamente, salvando así las dificultades que se plantean en relación con estas nuevas experiencias participativas ${ }^{22}$. De hecho, la Ley de la Toscana del 2013 excluye la posibilidad de acudir al referéndum consultivo cuando ya se ha optado por un instrumento de democracia participativa. Sin duda, esta exclusión cuenta con una finalidad muy clara como es la de tratar de consolidar estas prácticas con el compromiso tanto de los ciudadanos participantes como de los poderes públicos implicados. Sin este compromiso resulta evidente que la experiencia nacería viciada desde su origen porque, de hecho, la práctica ha ido demostrando cómo el desarrollo de estas experiencias no ha resultado nada fácil, por lo que sin un compromiso firme y existiendo la posibilidad de optar por instrumentos alternativos que resuelvan las dificultades de manera más sencilla, se conseguiría eliminar el objetivo de la deliberación, esto es, el

${ }^{22}$ Para RuIloba NúÑEZ, M. pese a la indudables potencialidades que presentan estas formas participativas, debe apostillarse que una corriente de escepticismo señala los problemas de sustentar todas las esperanzas en los procesos participativos, siendo las críticas más comunes aquellas que inciden en que con ellos se aumenta la lentitud de la toma de decisiones, se incrementan los costes y se procede a la defensa específica de intereses particulares por parte de sectores poco habituados a los procesos y con deficiente expertise técnica, jurídica o procedimental, así como su interés por el corto plazo y los intereses inmediatos e incluso la erosión que pueden provocar sobre las instituciones y partidos políticos al generar desconfianza en la capacidad representativa y la idea de defensa de intereses generales. (cursiva nuestra). RuILOBA NúÑEZ, M.: «¿Es el gobierno local un nuevo espacio para la participación ciudadana? El punto de vista de los alcaldes. El caso español», Estudios Políticos, 44, Instituto de Estudios Políticos, Universidad de Antioquia, 2014, p. 60. 
razonamiento y la búsqueda del consenso en la toma de decisiones tratando de compartir las responsabilidades en la búsqueda del «bien común».

Pero además, para poder deliberar y hacerlo de una manera auténticamente libre es importante tener en cuenta dos premisas. En primer lugar, este momento debe abrirse a los ciudadanos cuando todas las opciones son posibles y, en segundo lugar, es necesario que los participantes tengan acceso a una información suficiente y accesible que les deberá proporcionar la autoridad. Entraríamos en el llamado derecho a la buena administración como elemento integrante del concepto de Buen Gobierno.

Es en este momento cuando se plantean las nuevas posibilidades que ofrecen las tecnologías de la información y la comunicación en los procesos participativos. Las experiencias muestran que en estas prácticas concretas, las nuevas tecnologías se aplican de manera complementaria a las formas tradicionales en el momento previo de información, fundamentalmente por el coste económico que ello conlleva y atendiendo a la importancia del mayor grado de inclusión en este tipo de procesos ${ }^{23}$. La información que se transmita, sobre todo a los participantes, deberá ser clara, actualizada, objetiva, veraz, de calidad, relevante, accesible y exigible, insistiendo en aquella que realmente interesa a los ciudadanos y no tanto a los poderes públicos (GRAU, 2006, 29). Ello implica distinguir entre transparencia y transparencia accesible, insistiendo en la necesidad de que para conseguir un sistema realmente transparente no basta con el acceso a los datos (accesibilidad), sino también acompañar la información de la claridad suficiente para su comprensión, y más en el momento actual en el que internet también puede convertirse en un instrumento de opacidad que dificulta el control (CASTEL GAYÁn, 2013, 175).

El objetivo, sin duda, consiste en garantizar la autonomía ciudadana en este tipo de procedimientos. Supone un requisito que resulta a todas luces imprescindible desde cualquier perspectiva. Un requisito básico para la calidad misma del proceso.

Pero, además, igualmente imprescindible se presenta la necesidad de que existan reglas muy claras sobre tres puntos nucleares, en relación con estos procesos: quién decide, sobre qué se decide y cómo se resuelven los desacuerdos.

${ }^{23}$ Sobre las dificultades de la aplicación de las Tic's a los instrumentos de democracia participativa, sirvan como lecturas orientadoras, ColOMBO, C.: «Innovación democrática y TIC, ¿hacia una democracia participativa?», Rev. Internet, Derecho y Política, núm. 3, 2006, pp. 28-40; MARTí, J.L.: «Alguna precisión sobre las nuevas tecnologías y la democracia deliberativa y participativa», Rev. Internet, Derecho y Politica, núm. 6, 2008, pp 3-12; CRIADO, J.L.: «Construyendo la e-Administración Local», en Las Tecnologías de la Información y la Comunicación e internet en los Ayuntamientos de la Comunidad de Madrid, C.E.R.S.A.: Madrid, 2004; Cotino Hueso, L.: «Democracia electrónica», en Escobar Roca, G. (dir.), Curso Democracia y derechos humanos, Univ. de Alcalá, 2006, pp. 2-28, entre otras. 
En cuanto a quién decide, quién toma la decisión, podemos decir que en Europa, a diferencia de América Latina, la decisión la toma la autoridad. Es por tanto la legitimidad o el valor de la investidura electoral la que sustenta esta opción generalizada en nuestro continente ${ }^{24}$. Pero la pregunta que subyace a esta opción generalizada nos lleva a cuestionar qué grado de eficacia tendría, a efectos de participación ciudadana, si la decisión de los participantes sociales no va a ser vinculante para la autoridad/es que toma la decisión.

En relación con esta importante cuestión, merece especial mención, de nuevo, la regulación Toscana del año 2013 en la medida en que, aún manteniendo el poder de decisión de las instancias representativas locales, establece la necesidad de motivación cuando la autoridad se separe total o parcialmente del resultado del proceso. Con ello, se estaría facilitando un control político o rendición de cuentas a posteriori, también a través del peso de la argumentación ${ }^{25}$.

Por la complejidad de estos procedimientos de democracia participativa, la práctica nos ha ido mostrando que, junto a los actores protagonistas, se requiere además la presencia de otras figuras o instituciones de carácter mediador que garanticen, desde una posición neutral, la eficacia del proceso. La Ley regional de la Toscana del año 2007 así lo hizo con la llamada «Autoridad garante de la participación», diseñada con carácter unipersonal. Sin embargo, será la Ley del 2013 la que llevará a cabo su reconfiguración definitiva buscando una mayor independencia e imparcialidad en el ejercicio de sus funciones, teniendo en cuenta su papel decisivo en los momentos previos al procedimiento, mostrados durante la vigencia de la Ley del 2007, fundamentalmente en orden a cuestiones tan importantes como la admisibilidad del proceso cuando, por ejemplo, lo solicite un ente local o, la exclusión de de-

${ }^{24}$ Sin embargo, conviene distinguir, como así lo hace U. ALLEGRETTI el poder de decisión final, en manos de los órganos representativos, del resto de medidas que se puedan tomar de carácter técnico, obviamente en manos de burócratas y cuerpos técnicos que no cuentan con legitimación electoral. De hecho, la mayor parte de los ordenamientos hoy en día, remiten la adopción de medidas puntuales así como la gestión a estos cuerpos administrativos. Vid.: AllegretTI, U.: «Il camino accidentato di un principio costituzionale: Quaranta anni di pratiche partecipativa in Italia», $R A I C, n{ }^{\circ} 1 / 2011,2011$, p. 14 (consultado 12-11-2013).

${ }^{25}$ La Regulación de Emilia Romagna sobre los procedimientos participativos (Ley 8/2008, de 27 de mayo y Ley 3/2010, de 9 de febrero) prevé también el apoyo regional a este tipo de procedimientos. Tiene muchos puntos en común con la regulación Toscana, sobre todo la Ley del 2010 que efectivamente establece que las autoridades deberán tener en cuenta el resultado de las deliberaciones, pero en el caso de que sus decisiones se alejen en todo o en parte de la propuesta participada, las autoridades deberán expresar de manera razonada, los motivos de dicha medida (art 10.4 de la Ley 3/2010). Cfr VIZIOLI, N.: «La democracia participativa en la Legislación regional italiana», Revista catalana de dret públic, n. ${ }^{\circ} 48,2014$, pp. 201-204. 
terminados sujetos en el procedimiento. Así, la Ley del 2013 establece que los miembros de este órgano colegiado serán nombrados entre el Consiglio y el Presidente de la Giunta, con un mandato de cinco años. Sin embargo, esta ley sigue manteniendo unos criterios muy vagos e imprecisos de actuación, lo que continúa otorgando a este órgano un considerable grado de discrecionalidad a la hora de tomar decisiones. Así, la selección de algunos participantes, o de otras cuestiones en la Ley del 2013, se fundamenta en criterios como el del interés sobre el territorio, en el objeto del proceso o/y en la utilidad de la intervención, criterios todos ellos que siguen permitiendo grandes dosis de discrecionalidad en la decisión.

Surge entonces la cuestión del control y su importancia, y no sólo en relación con las decisiones de esta Autoridad, sino también en relación con el rendimiento del recurso participativo en sí, y con el grado de cumplimiento de la decisión tomada. Y es que, con carácter general en relación con estos procedimientos podemos decir que los mecanismos de control, a nivel legal, están poco o nada desarrollados y, en este sentido, sería conveniente para la buena marcha de este tipo de procedimientos, así como para su posterior consolidación, profundizar más en este aspecto a todas luces muy relevante.

Prueba de ello, por ejemplo, es el caso que se plantea en cuanto al control de la decisión de la Autoridad garante de la participación en el supuesto de rechazar una solicitud de proceso participativo o de excluir, por ejemplo, la participación de determinados sujetos. Se cuestiona por un sector de la doctrina italiana si en estos casos sería posible el recurso a la tutela judicial, teniendo en cuenta que la Ley Regional Toscana de 2013 configura la participación ciudadana como un derecho ${ }^{26}$.

Muchas dudas surgen a este respecto partiendo del difícil encaje de estos mecanismos en las categorías clásicas del principio de legalidad y de la tutela jurisdiccional. Pero teniendo en cuenta que nos encontramos en un momento que podríamos calificar de «experimentación»e «inmadurez» de los instrumentos de democracia participativa, no se debería despreciar esta posibilidad y, algunas voces defienden que, en determinadas hipótesis, debería considerarse el derecho a la defensa judicial (U. AlLEGRETTI, 2007, 801-802; S. CASSESE, 2007, 14 y ss). Sin embargo, en mi opinión, el recurso a la tutela judicial supondría dilatar en el tiempo la resolución del conflicto, perjudicando gravemente la naturaleza y finalidad del procedimiento participativo en sí, además de agravar uno de los defectos que se le critican a estas prácticas

${ }^{26}$ Art 1.1 «La Regione, ai sensi dell'articolo 3 dello Statuto, riconosce il diritto dei cittadini alla partecipazione attiva all'elaborazione delle politiche publiche regionali e local, nelle forme disciplínate dalla presente legge».

2.-b. «promuovore la partecipazione come forma ordinaria di amministrazione e di governo delle Regione in tutti i settori e a tutti livelli amministrativi». 
como es su lentitud en la toma de decisiones que con el recurso judicial se alargaría aún más, y todo ello sin contar con el coste económico que tiene la tutela judicial para las partes.

Sin embargo, ello no significa que se deba renunciar al control de las decisiones de esta Autoridad. Precisamente la motivación de sus decisiones será clave para permitir su control; control que podría recaer, en un primer momento, en la propia Autoridad garante de la participación o figura mediadora, para que pudiera reconsiderar su decisión y, en un segundo momento, tras una confirmación de la decisión tomada por la Autoridad, buscar la tutela del derecho en lo que se conoce como instrumentos de defensa cívica, cuya función original es precisamente el control de la mala administración y la defensa de los derechos de los ciudadanos administrados ${ }^{27}$.

En cuanto a la fiscalización del rendimiento en sí del procedimiento, tampoco se contempla legalmente, pero en mi opinión, por ejemplo en el caso de la Toscana, el hecho de haberse fijado un período determinado de vigencia en el propio texto de la ley del 2007, ya encerraba claramente esta intención con la finalidad de perfeccionar el rendimiento de estos procedimientos a través de una ley posterior, como así sucedió. Sin embargo, el texto vigente no recoge ningún mecanismo que permita un control concreto y a posteriori de cada procedimiento celebrado, ni tampoco un seguimiento de las decisiones tomadas. En general, las distintas normativas guardan silencio sobre esta cuestión y, sin embargo, sería igualmente conveniente, en aras de la consolidación de estas prácticas, fijar mecanismos que permitieran la rendición de cuentas, por ejemplo, a través de asambleas puntuales meramente informativas u otros canales de información que comunicaran con transparencia a los interesados, los avances o las dificultades que se vayan produciendo en cada caso tras la decisión tomada, y no como ocurre en la actualidad en donde la posibilidad de que se lleve a cabo este seguimiento depende del criterio discrecional de las autoridades regionales o locales.

En esta línea y, más concretamente, en relación con los Presupuestos Participativos, algunos autores abogan, por ejemplo, por la fórmula de los presupuestos por objetivos (ROMERO, J. Y FARINÓs, J., 2011, 305-307), enlazando este mecanismo con el objetivo del desarrollo territorial sostenible aplicado al ámbito de la ciudad, y donde esta práctica debe ser entendida como proyecto de futuro construido por todos, generaciones presentes y fu-

${ }^{27}$ El Estatuto de la Región de Toscana de 19 de julio de 2004 de hecho prevé en el art 56, dentro del Título V, sobre órganos de tutela y garantía, la figura del Difensore Civico, en la que recoge las notas que caracterizan a esta institución y que sin duda se ajustan de manera idónea al tipo de control que necesitarían estas prácticas participativas: Art 56, 1.- Il Difensore Civico regionale garantisce a tutti la tutela non giurisdizionale nei casi di cattiva amministrazione, svolgendo anche attività di mediazione. 
turas, haciendo posible el diseño y el control de los presupuestos a corto, medio y largo plazo. Con ello sería posible evitar rupturas en su práctica, por ejemplo como consecuencia de la alternancia política, fortaleciendo así la idea de implicación permanente de todos, ciudadanos y operadores políticos, en el gobierno de su ciudad ${ }^{28}$. Precisamente Gomes CANOTILHo $(2010,343)$, haciendo referencia a la Declaración de Río del 2010, incide en la idea de «responsabilidad compartida» como un nuevo principio que implica la necesidad de nuevos esquemas de «gobernanza» que den espacio a las exigencias de participación, información y de envolvimiento en procesos decisorios y de buena administración que legitimen, en términos efectivos, una división de responsabilidad de los ciudadanos ${ }^{29}$. Esto es, lo que ya apuntamos en palabras de AHLERT (2007), «responsabilidad con la colectividad».

Después de analizar la importancia de la implicación autoridades-sociedad a la hora de intervenir y tomar decisiones en estos procedimientos, nos resta afrontar otros dos puntos que también debieran contar con un reflejo legal por los mismos motivos ya apuntados. Estos puntos serían: «sobre qué se decide» y «cómo se resuelven los desacuerdos», dos cuestiones que, desde el punto de vista legal, también deben ser reformulados.

Tanto en los debates públicos como en los presupuestos participativos las experiencias reflejan la existencia de regulaciones al respecto. Los Presupuestos participativos implican dejar en manos de la deliberación el presupuesto local o parte del presupuesto local, que obviamente variará anualmente en función de las cantidades con las que cuente la ciudad. Por ello resulta igualmente positivo que sea la propia comunidad, en algunas experiencias en confluencia con las autoridades públicas, quienes valoren sus necesidades sociales y, no sólo y en todo caso a corto plazo sino, también y como hemos apuntado, como proyecto de futuro, incidiendo en objetivos como la cohe-

${ }^{28}$ Sobre el presupuesto por objetivos, la Región del Lazio, por ejemplo, parece haber recogido una fórmula en este sentido al adoptar como práctica de democracia participativa, los Presupuestos Participativos de base trienal, que son revisados y actualizados por los ciudadanos y representantes políticos anualmente y, por tanto, aplicando un seguimiento continuado a modo de control sobre los resultados aprobados en la ciudad.

${ }^{29}$ Idea que queda muy claramente reflejada en el Principio 10 de la Declaración, «El mejor modo de tratar las cuestiones ambientales es con la participación de todos los ciudadanos interesados, en el nivel que corresponda. En el plano nacional, toda persona deberá tener acceso adecuado a la información sobre el medio ambiente de que dispongan las autoridades públicas, incluida la información sobre los materiales y las actividades que encierran peligro en sus comunidades, así como la oportunidad de participar en los procesos de adopción de decisiones. Los Estados deberán facilitar y fomentar la sensibilización y la participación de la población poniendo la información a disposición de todos. Deberá proporcionarse acceso efectivo a los procedimientos judiciales y administrativos, entre éstos el resarcimiento de daños y los recursos pertinentes». 
sión social y la mejora de la calidad de vida. El diseño de los distintos procesos varía en función de los contextos, de ahí que las regulaciones, en términos generales, sean meramente indicativas. De ahí que sea importante la existencia de controles.

Los Debates Públicos sobre grandes obras, de corte francés, que son los más extendidos, ciñen su objeto a la deliberación sobre grandes obras de infraestructura que pueden suponer grandes costes materiales para la comunidad así como, sobre todo, su oportunidad en momentos determinados ${ }^{30}$. La regulación Toscana del 2013, por ejemplo, recoge una definición precisa del debate público, así como el tipo de obras que deben ser sometidas de forma obligada a este tipo de procedimiento, reduciendo así en cierta medida, el ámbito de discrecionalidad de la Autoridad garante de la participación (A. FLORIDIA, 2007, 287).

En general, en las experiencias Italianas, como es el caso citado así como el de la Región de Emilia Romagna, la legislación no opta por procedimientos participativos específicos, sino que más bien opta por la definición de un tipo genérico $^{31}$, otorgando más flexibilidad procedimental en función de las necesidades y cuestiones a $\operatorname{tratar}^{32}$. Por otro lado, ambas legislaciones resultan más concretas en relación con aquellas cuestiones que se pretenden fomentar como son la continuidad de estas prácticas, su carácter inclusivo, así como la transpa-

${ }^{30}$ La especificidad del debate público consiste en que nace para resolver un conflicto ya iniciado o que se puede prever fácilmente. Las grandes obras tienden a encontrar una doble oposición: por un lado la de los residentes que temen una invasión de su territorio y alteraciones en sus ritmos de vida, peligros para la salud, devaluación de sus casas...y por otro lado los ecologistas que se preocupan por cuestiones más generales como son la utilidad de las obras, o el modelo de desarrollo en el que se inspiran, proponiendo medidas menos invasivas o que respondan a un modelo de vida alternativo. Sobre las especificidades del modelo francés y algunas experiencias en Italia vid BoBBIo, L. (2010, 190 y ss).

${ }^{31}$ La Ley 3/2010 Toscana, en su art 10.3 recoge «por proceso participativo se entiende un proceso de discusión organizada que se inicia en relación con un proyecto de futuro o con una futura norma en el marco de la competencia de las Asambleas electivas o de los Gobiernos, regionales o locales, con vistas a su elaboración, poniendo en comunicación a actores e instituciones, a fin de conseguir la completa representación de las posiciones, de los intereses o de las necesidades sobre la cuestión, además de llegar a una medicación o negociación, buscando un acuerdo de las partes implicadas sobre la cuestión objeto de los actos de discusión».

32 Pensemos en los distintos contextos y en la presencia de catástrofes naturales que exigen una reconstrucción como la sucedida en Friuli después del terremoto de 1976 o de Umbría-Marche en el año 1997, donde como explica U. AlLEGRETTI, la coyuntura, una situación particular, puede explicar, más allá de las ideas generales u opciones ideológicas, la aplicación a un cierto contexto y a situaciones de este tipo, el mejor resultado, como así fue; una reconstrucción desde la colaboración autoridades y ciudadanos. Vid.: Allegretti, U.: «Democrazia partecipativa: un contributo alla democratizzazione della democracia», en Democrazia partecipativa. Esperienza e prospettive in Italia e in Europa, U. Allegretti (a cura di), Firenze University Press, 2010, p. 19. 
rencia informativa ${ }^{33}$. Luego es el procedimiento el que goza de flexibilidad, tratando de buscar mayor eficacia práctica, pero no en cuanto a su objeto. Estamos de acuerdo con U. ALLEGRETI (2010) cuando tras analizar estas primeras experiencias italianas concluye que, al menos en la fase experimental en la que se encuentran muchos territorios, resulta conveniente que tales fuentes normativas no contengan más que las autorizaciones y prevean la imposición de formas de participación solo para algunos actos que requieran de unas necesidades específicas, como son por ejemplo, los planes urbanísticos, las intervenciones sobre el medio ambiente, algunos procedimientos en materia de sanidad, así como los Presupuestos. Para el autor Italiano, en estas primeras fases resulta más oportuno «un espíritu inventivo de las modalidades de actuación».

En cuanto al último punto, cómo deben resolverse los desacuerdos, ya apuntamos en páginas precedentes cómo el voto no puede ser descartado como mecanismo de decisión en estas prácticas participativas porque, en algunos momentos, pueden darse situaciones complejas que requieran el uso de esta técnica tras la deliberación propiamente dicha, sin que se haya podido llegar a un resultado concreto. Bien es cierto que las técnicas son distintas, pero la presencia de situaciones «difíciles» puede llevar a la combinación de éstas en busca de la mejor solución posible. En las sociedades modernas existen tres modos de tomar decisiones: la votación, la negociación y la deliberación (ELSTER, 1986). Mientras la votación supone una agregación de voluntades de acuerdo con la regla de la mayoría, en la negociación rige la regla de la unanimidad que debe llevar al compromiso o acuerdo negociado de todos y cada uno de los participantes. Ambas reglas se contraponen a la deliberación, en la medida en que esta última busca, entre otros fines, transformar las preferencias, que los participantes en el proceso aprendan los unos de los otros matizando los distintos puntos de vista, redefiniendo los problemas e incluso, inventando nuevas opciones (L. BobBIo, 2002, 105). Sin embargo, LANZARA $(2005,70)$, desde una concepción más realista, mantiene que la confianza en la virtud de la democracia deliberativa debe ser al menos atemperada desde la atenta valoración de sus límites y de sus posibles distorsiones, en la medida en que puede llegar a convertirse en una práctica igual de vulnerable que la democracia agregativa $^{34}$. En definitiva, momentos participativos diferentes, capaces de ser conciliados, para llegar al mejor resultado consensuado.

${ }^{33}$ Cfr Vizioli, N.: «La democracia participativa en la Legislación regional italiana», Revista catalana de dret públic, n. ${ }^{\circ}$ 48, 2014, p. 203.

${ }^{34}$ Por otro lado, para L. BoBBIo desde un punto de vista estratégico, existen momentos deliberativos que resultan necesarios. Parte del supuesto en que una Administración Pública debe tomar una decisión polémica de cara a los ciudadanos, por sus efectos negativos, por sus altos costes, por sus beneficios difusos, etc, resultando estratégicamente 


\section{BIBLIOGRAFÍA}

AHLERT, A.: «Etica y Derechos Humanos: principios educacionales para una sociedad democrática», Polis: Revista Latinoamericana, n. ${ }^{\circ}$ 16, 2007, ISNN-e 07186568, 2007 (consultado 4-12-2013).

AlLEGRETTI, U.: «Il camino accidentato di un principio costituzionale: Quaranta anni di pratiche partecipativa in Italia», RAIC, $n .^{o} 1 / 2011,2011$ (consultado 12-11-2013).

- : ¿Democrazia partecipativa: un contributo alla democratizzazione della democracia», en Democrazia partecipativa. Esperienza e prospettive in Italia e in Europa, U. Allegretti (a cura di), Firenze University Press, 2010, pp 5-46.

- :Procedura, procedimento, proceso. Un'ottica di democracia partecipativa», R. Diritto Amministrativo, n. ${ }^{\circ}$ 4, 2007, pp. 779-804.

Allegretti, G.: l'insegnamento di Porto Alegre: autoprogettualità come paradigmo urbano, Alinea, Florencia, 2003.

BIFULCO, R.: «Democracia deliberativa y democracia participativa», www.astridonline, pp. 1-10, 2010 (consultado 7/11/13).

BLANCO, I.: «Presupuestos participativos y democracia local: una comparación entre las experiencias brasileñas y españolas», documento presentado en el VII Congreso Internacional del CLAD sobre la Reforma del Estado y de la Administración Pública, Lisboa, 8 al 11 de octubre, 2002.

BLANCO, I. y GoMÁ, R.: «Gobiernos Locales y redes participativas: retos e innovaciones», Revista del CLAD. Reforma y Democracia, 26, 2003, pp. 1-15.

BoввiO, L.: «Come smaltire i rifiuti. Un esperimento di democrazia deliberative», Stato e Mercato, n. 64, 2002, pp. 101-141.

- - «Dilemmi della democracia partecipativa», Democrazia e Diritto, 44, 2006, p.11-26.

— : «As especifidades do debate público sobre as grandes infraestruturas. O caso de Génova», Revista Crítica de Ciências Sociais, 91, URL http://rccs.revues. org/4201, 2010, pp. 189-203, (consultado 15-10-2014)

BobBio, N.: El Futuro de la Democracia, Plaza\&Janés, 1985, pp. 7-221.

BRUGUÉ, Q. y PARÉs, M.: «Entre la deliberación y la negociación: el caso de la Mesa de la Montaña de Aragón», REP (Nueva Época), n. ${ }^{\circ}$ 158, Madrid, 2012, octubrediciembre, pp 75-101.

ventajoso compartir responsabilidades con la comunidad a través de una «arena» inclusiva y, por ello, elegir un foro de discusión que incluya a la comunidad afectada. De esta forma, la Administración Pública es la que anticipa los conflictos, abriendo la participación a eventuales opositores y utilizando el procedimiento deliberativo como modalidad de construcción preventiva del consenso. Vid.: BobBio, L.: «Come smaltire i rifiuti. Un esperimento di democrazia deliberative», Stato e Mercato, n. 64, 2002, pp. 101-141

Para el autor, la constitución de una arena deliberativa (multilateral) permitiría superar de modo eficaz el problema de los poderes de veto que las comunidades locales pueden ejercer contra proyectos de interés general que se perciben como una amenaza para los propios intereses. (citado por CATALDI, L.: «Promesse della Democrazia Deliberativa: Un'alternativa alla Democrazia del voto?», Centro Einaudi, Laboratorio di Politica Comparata e Filosofia Pubblica, Working Paper-LPF n. ${ }^{\circ}$ 3, 2008, p. 27). 
CApograssi, G.: La nuova democracia diretta, 1. ${ }^{\circ}$ vol., Roma, 1922.

CARLASARRE, L.: «Priorità costituzionale e controllo sulla destinazione delle risorse», Costituzionalismo.it/ Fasc 1/2003, pp. 1-22. (Consultado 6/11/2013), 2003 ${ }^{\mathrm{a}}$.

- : «La Rappresentanza Política: un concetto complesso», Seminario 2002/Associazione per gli Studi e le Ricerche Parlamentari, Torino, G. Giappichelli, 3, 2003b, pp 57-71.

CASSESE, S.: «La partecipazione dei privati alle decisioni pubbliche. Saggio di diritto comparato», Riv. Trimestrale di Diritto Pubblico, Giuffre, Fasc. 1, 2007.

CAstel Gayán, S.: «Reflexiones sobre el marco normativo del Buen Gobierno», Cuadernos Manuel Giménez Abad, núm. 6, diciembre 2013, pp. 168-180.

CATAldi, L.: «Promesse della Democrazia Deliberativa: Un'alternativa alla Democrazia del voto? », Centro Einaudi, Laboratorio di Politica Comparata e Filosofia Pubblica, Working Paper-LPF n. ${ }^{\circ}$ 3, 2008, pp 2-38.

Cocco, G.: «Federalismo municipale partecipato», Costituzionalismo.it, Fascicolo 2/2009), 2009, pp 1-28, (consultado 12/7/2013).

Colombo, C.: «Innovación democrática y TIC, ¿hacia una democracia participativa?», Rev. Internet, Derecho y Politica, núm. 3, 2006, pp. 28-40.

Cotino Hueso, L.: «Democracia electrónica», en Escobar Roca, G. (dir.), Curso Democracia y derechos humanos, Univ. de Alcalá, 2006, pp. 2-28.

CRIADO, J.L.: «Construyendo la e-Administración Local», en Las Tecnologías de la Información y la Comunicación e internet en los Ayuntamientos de la Comunidad de Madrid, C.E.R.S.A., Madrid, 2004.

Criado De Diego, M.: «Sobre el concepto de representación política: lineamientos para un estudio de las transformaciones de la democracia representativa», Rev. Derecho del Estado, núm. 28, enero-junio 2012, pp. 77-114.

Elster, J.: «The Market and the Forum», en Elster, J. y Hylland, A. (coord.), Foundations of social choice Theory, Cambridge University Press, 1986.

FERrara, G.: «I Presupposti della democracia», Costituzionalismo.it, Fasc 3/2009, 2009, pp 1-13 (Consultada 8/01/2014).

FIoravant, M.: La Costituzione, Il Mulino, 1999, pp 3-184.

FLORIDIA, A.: «La democracia deliberativa, dalla teoría alla procedure. Il caso della legge regionale toscana sulla partecipazione», Riv. Le istituzioni del federalismo, Fasc. 5, 2007, pp 1-44.

Font, J. (Coord.); Ciudadanos y decisiones públicas, Ariel, Barcelona, 2001.

Garrorena Morales, A., «Representación política y Constitución democrática», Jornadas: El parlamento y sus transformaciones actuales. Estímulo a una reflexión. Cuadernos Civitas, 1991.

Ganuza Fernández, E. Y Alvares de Sotomayor, C. (dirs), Democracia y Presupuestos Participativos, Icaria, Barcelona, 2003.

Gret, M. y Sintomer, Y.: Porto Alegre: la esperanza de la democracia, Debate, Barcelona, 2003.

Gomes Canotilho, J.J.: «Principios y «nuevos constitucionalismos». El problema de los nuevos principios», ReDCE, Año 7, Núm. 14, julio/diciembre 2010, pp. 321-364. 
GRAU, C.: «La transparencia en la gestión pública. ¿Cómo construirle viabilidad?», Estado, Gobierno y Gestión Pública, Revista Chilena de Administración Pública, n. ${ }^{\circ} 8,2006$, pp.22-44.

HÄBerle, P.: Pluralismo y Constitución: Estudios de Teoría Constitucional de la sociedad abierta, ed. E. Mikunda, Tecnos, Madrid, 2002.

LANZARA, G.F. (X), «La deliberazione come indagine pubblica», en Pellizoni, L.: (2005, a cura di), La deliberazione pubblica, Roma, Meltemi, 2005, pp. 51-73.

LeVINE, D. H. y MolinA, J. E.: «La calidad de la democracia en América Latina: una visión comparada», América Latina Hoy 45, 2007, pp. 17-46.

LIETO, S.: «Il rapporto tra il referendum e la democracia della rappresentanza nell'attuale crisis del sistema político», Costituzionalismo.it, Fasc 1/2012 (consultado 13 enero 2014), 2012, pp 1-23.

MARTí, J.L.: «Alguna precisión sobre las nuevas tecnologías y la democracia deliberativa y participativa», Rev. Internet, Derecho y Política, núm. 6, 2008, pp 3-12.

PÉREZ CASTELl, M.: «La experiencia de los presupuestos participativos en Albacete», Temas para el Debate, n. ${ }^{\circ}$ 113, abril, 2004, pp. 54-57.

Pizzorusso, A.: «Democrazia partecipativa e attività parlamentare», en Studi in onore di Antonio Amorth, vol II, Scritti di diritto costituzionale e altri, Milan, Giuffrè, 1982, pp. 133-142.

SKINNER, Q.: El artista y la filosofía politica. El Buen Gobierno de Ambrogio Lorenzetti, 2009.

Ramos, A. y Faria, C.F.: «Las Conferencias de Políticas Públicas en Brasil: hacia un sistema integrado de participación y deliberación a nivel nacional», Revista Española de Ciencia Política, n. ${ }^{\circ}$ 32, julio, 2013, pp. 43-63.

ROMERO, J. y FARINÓs, J.: «Redescubriendo la Gobernanza más allá del Buen Gobierno. Democracia como base, desarrollo territorial como resultado», Boletín de la Asociación de Geógrafos Españoles (BAGE), núm. 56, 2011, pp. 295-319.

RUANO DE LA FuENTE, J.: «Contra la participación: discurso y realidad de las experiencias de participación ciudadana», Política y Sociedad, 47, 2010, pp. 93-108.

RUILOBA NúÑEZ, M.: «¿Es el gobierno local un nuevo espacio para la participación ciudadana? El punto de vista de los alcaldes. El caso español», Estudios Políticos, 44, Instituto de Estudios Políticos, Universidad de Antioquia, 2014, pp. 55-73.

SinTOMER, Y.: «Los Presupuestos participativos en Europa: retos y desafíos», Rev. del CLAD Reforma y Democracia, n. ${ }^{\circ} 31$, Febrero 2005, Caracas, 2005, pp. 1-17.

SKINNER, Q.: El artista y la filosofia política. El Buen Gobierno de Ambrogio Lorenzetti, Introducción de Eloy García, Ed. Trotta, 2009, pp. 9-146.

SubIRATS, J.: «¿Nuevas vías de participación ciudadana en los gobiernos locales?», en La Ley de Modernización del Gobierno Local, Fund. Carles Pi y Sunyer D’Estudis Autonomics i locales. Estudios 17, 2004, pp. 39-46.

Viola, F.: La Democracia deliberativa entre constitucionalismo y multiculturalismo, (trad. de J. Saldaña), México, UNAM, Instituto de Investigaciones Jurídicas, 2006, pp. 1-89.

VIZIOLI, N.: «La democracia participativa en la Legislación regional italiana», Revista catalana de dret públic, n. ${ }^{\circ} 48,2014$, pp. 187- 205.

ZAFRA, M.: «Órganos y estructuras de participación social», La Ley de Modernización del Gobierno Local, Fund. Carles Pi y Sunyer D'Estudis Autonomics i locales. Estudios 17, 2004, pp. 47-56. 
TITTLE: Citizen Participation in public affairs and its contribution to the quality of democracy. Reflections with regards to some participative experiences

RESUMEN: En el presente artículo se trata de analizar, ante el déficit democrático que viven las sociedades actuales, nuevas formas de participación ciudadana en la toma de decisiones que tradicionalmente pasan por la sola voluntad de nuestros representantes políticos. El sistema de representación, pilar en el que se sustentan los derechos de participación politica con carácter general, necesita ser reforzado con otros instrumentos que impliquen un mayor y permanente protagonismo de los ciudadanos en la arena política. El ámbito local, como hábitat natural para poner en marcha instrumentos de democracia participativa, resulta idóneo si queremos recuperar y consolidar conceptos como responsabilidad, cultura cívica y sobre todo, ética política tan en declive en los últimos años. La búsqueda del bien común debería marcar una nueva forma de gobernary ser gobernados a través de los clásicos conceptos de Gobernanza y Buen gobierno, hoy más actuales que nunca. Este tipo de instrumentos participativos, aunque en fase de experimentación, nos van a ir mostrando su potencialidad así como también sus debilidades para el objeto que se pretende. Será principalmente la experiencia Italiana la que nos sirva de hilo conductor de nuestro análisis y reflexión.

Palabras ClaVE: Constitución; Gobernanza y Buen Gobierno; democracia deliberativa.

ABSTRACT: Due to the democratic deficit in the nowadays societies, new forms of citizen participation in decision making which used to belong only to our political representatives» will are analysed in this article. The representation system, the essential pillar on which the political fundamental rights rest, needs to be strengthened with other instruments which imply a stronger and more significant role in the political field. The local sphere, natural habitat to implement democratic participation instruments, is eligible to recover and consolidate concepts such as responsibility, public spirit and mainly public ethics so in decline in recent years. The quest for the common good should make a new way of governing and being governed by the old concepts of Governance and Good Government, nowadays more relevant than ever. Although it is still in an experimental stage, this kind of participative instruments will show its potential effects and weaknesses for the intended aim. The Italian experience will be mainly the thread for this analysis.

KEYWORDS: Costitution; Governance and right Government; deliberative democracy.

RECIBIDO: 12.06 .2015

ACEPTADO: 09.12.2015 